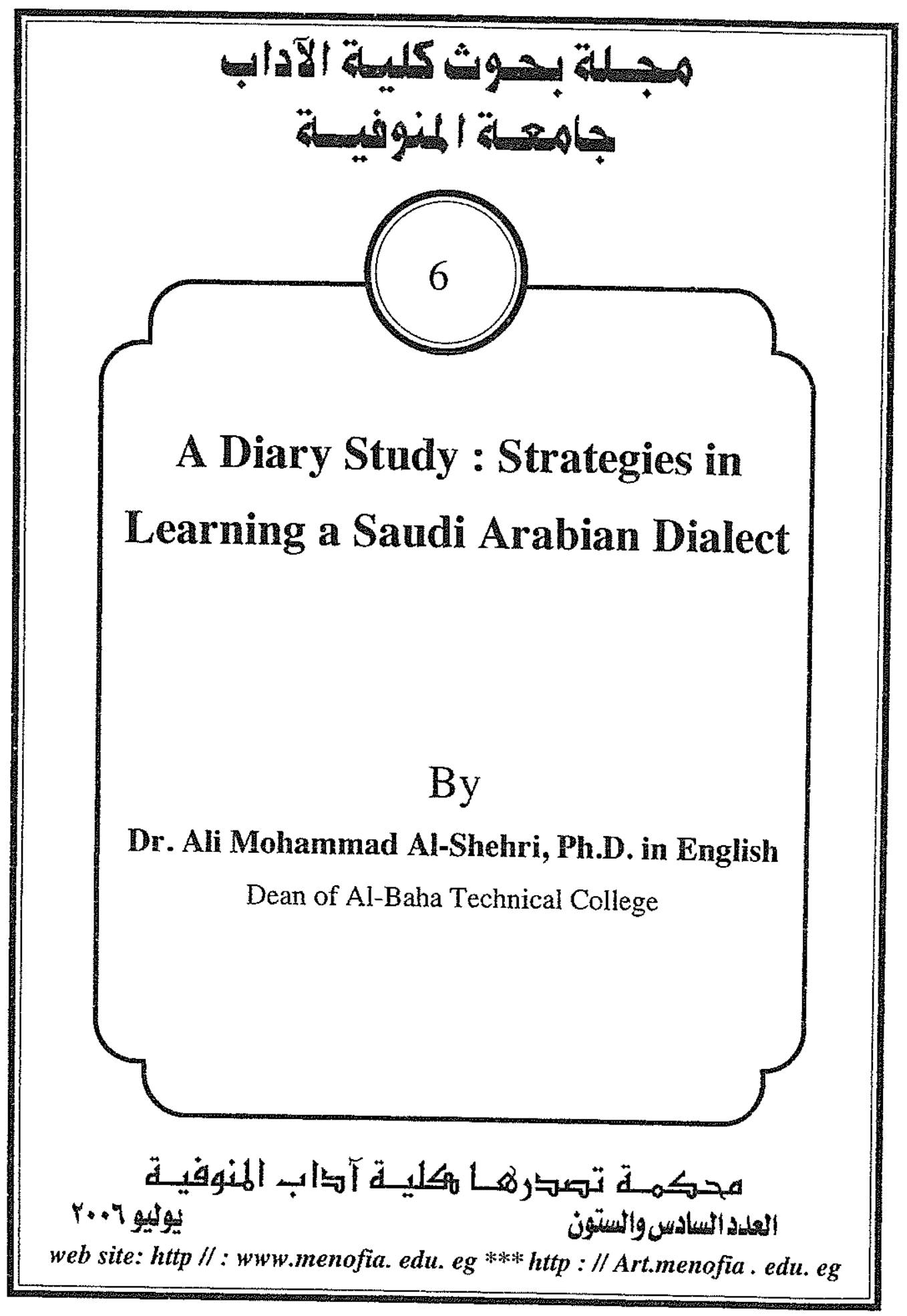





\begin{abstract}
This diary study is investigating the strategies used by an experienced EFL teacher, when he was learning a second language, Arabic in this case, in a short individualized oral course with formal and informal conversational classes taught by an Arabic speaker. The purpose is to observe: a) the learning and communication strategies used by the learner; b) the kind of metalinguistic knowledge that the learner employs to aid the participant in his learning; and c) the inferences and hypothesis made during the learning process and how these were confirmed or unconfirmed.
\end{abstract}

The learner participant's native language is Spanish and she also speaks fluently Lithuanian, and English. The participant will be asked to keep a journal of her experiences during the learning process which will last eight weeks. The entries will be written in a semisystematic way. The teacher (the researcher) will also keep a diary of the learning aspects where he will note down the strategies used by the learner and the difficulties experienced in the process of learning the language.

Both of these data sources will be analyzed to find patterns, regularities or salient events. It assumed that the analyses would indicate that there are multiple strategies being used, such as memory, cognitive or metacognitive strategies.

\title{
The Literature Review
}

Most language learning processes and strategies are not observable because they occur within the learner and do not necessarily involve production. Cohen (1984) states that classroom observations are useful in that we can record physical movements of our students, the words they utter, etc., "but [we] cannot capture what they are thinking about, how they are thinking, or how they feel. Thus, observation regarding language learning behavior is generally limited to students who speak out'loud " (p.101). Besides there is a need to acquire precise and factual insights about learners conscious thought processes, that is, those that they are aware of. Therefore, in order to access these phenomena, we are urged to recur to naturalistic research methods (Ochsner, 1977; Brown, 198?;) that include some kind of verbal reports from learners themselves (Scovel, 1979, Bailey, 1983). These methods that allow some kind of access to learners' internal processes and knowledge have been borrowed from related field of studies such as linguistics, sociology and psychology. They are known 
as introspective methods (Faerch \& Kasper, 1987) as well as by a variety of other names such as verbal reports, verbal statements, verbal data, verbal protocols, thinking-aloud and retrospection. Faerch \& Kasper, (1987) mention that a common feature of these introspective methods is that " they use data, informants' own statements about the ways they organize and process information, as an alternative or supplement to inferring their thoughts from behavioral events" (p.9). Furthermore, they state that during the realm of behaviorism introspection had been seen as a forbidden procedure but with the paradigm shift towards a more mentalistic conception of language, such as cognitivism, new gateways were opened for researchers to inquire into mental processes and strategies employed by language learners.

Radford \& Burton (1974) give a clear view of the role of introspection in second language learning and the current feeling in the field of its relevance and appropriateness of use, they state "

Introspection gives us information about experience. It yields data otherwise inaccessible. It may, besides, bring to light facts that might otherwise be overlooked, or stimulate us to ask new questions. Like any technique, it has peculiar difficulties, especially when used in odd circumstances. These, however, are the hazards of science ( $p$. 395).

Cohen (1984) mentions as introspective methods three basic categories, which are self-report, self-observation and self-revelation. Self-reports are learner statements based more on leamers' beliefs on how they learn and are rarely based on the observation of any happening. Self-observation refers to the inspection of specific language behavior, either while the information is still in the shortterm memory, i.e., introspectively, or after the event, i.e., retrospectively (usually after twenty seconds or so). Retrospection can be immediate (e.g., within say, an hour of the event) or delayed (a few hours, days, or even weeks after the event) (p.102).

The last one, 'self-revelation' takes place simultaneously when the action (strategy, conscious thought process, etc.) is occurring and the learner thinks-aloud and states his thoughts, feelings, etc.

In relation to data from self-observation Cohen \& Hosenfeld (1981) make a clear difference of the thin line between introspection and retrospection when they state that what started as introspection 4

may wind up as retrospection. They explain that" if the introspection 
of the mental state is immediate (within a few seconds), then we will refer to it as "introspection". If, however, observation does not take place at once, we will refer to this as "retrospection (p.290).

Furthermore these two authors make a difference between two kinds of retrospection: 'immediate retrospection' (recollection right after the event) and 'delayed retrospection' (recollection after more time has elapsed -say, an hour, a day, or even a week).

We must remember as Gillette (1987) states that "Language is ... a human activity which, as such has rarely proved to be easily quantified" (p.269) and it is through introspective methods such as self-observation that we can help us gain access to aspects of language learning that would have been unapproachable to inquiry before.

These self-observations, which use delayed retrospection, can take the form of a language learner diary where "daily events and the thoughts and feelings related to them [are recorded] in a log-like fashion, paying particular attention to cross-cultural adjustments and efforts made and avoided in learning the target language, both in and out of class" (Schumann and Schumann, 1977, p.243). Bailey and Ochsner (1980) define a diary study as: "A diary in second language learning, acquisition or teaching is an account of a second language experience as recorded in a first person journal... the central characteristic of the diary studies is that they are introspective: the diarist studies his own teaching or learning (p.189)".

Many researchers who favor introspective methods for second language research mention that diary studies can help learners report on affective factors, language learning strategies, and their own perceptions -facets of the language learning experience which are normally hidden or largely inaccessible to an external observer.

Furthermore, Bailey (1983) mentions that in many diaries the personal language learning histories of the learners are stated. The purpose of these as Bailey (1983) explains are "that they will contribute to an understanding of the personal factors involved in the current language learning experience" (p.71) because each leamer's history brings unique elements that affect the learning process of the individuals involved. Only by knowing their history can we understand how the interplay of these distinct elements cause a specific conduct or performance. It is through self-observation and self-monitoring that an individual can open the doors to his or her internal world of learning and show the paths used to acquire the desired knowledge. Learner diaries not only uncover a hidden realm 
of personal unique learner variables but as well provide developmental data, which can help us understand and augment our current knowledge of second language learning (Bailey, 1983, Long, 1979, Schumann and Schumann, 1977).

Another benefit of diary studies is that they allow teachers to understand what their learners are going through, what learners are doing when they learning, so that teachers can profit from the information found in the diaries and reorganize their curriculum towards more flexibility and creativity in learning (Oxford, Lavine, Felkins, Halloway \& Saleh, 1996, ).

Of course, there are weaknesses to these types of studies such as the ones pointed out by Schmidt and Frota (1988) where they state that diaries are "... idiosyncratic and of dubious generalizability, what they report is subjective, already filtered through perceptions and possible the biases of the learner, and exceeding difficult to verify" (p.338).

In the present study a learner (called from now on the learner) will study Arabic orally in short individualized program course taught by a native speaker of this language (called the teacher). The purpose of this program is to observe and monitor through self-kept diaries (one by the learner and another one by the teacher): a) the learning and communication strategies used by the learner; b) the kind of metalinguistic knowledge that she employs to aid her in her learning; and c) the inferences and hypothesis made during the learning process and how these are confirmed or disconfirmed.

\section{METHODOLOGY}

\section{i) Participants: (The learner)}

The learner kept a joumal of her experiences and observations during the learning process approximately during the six-week period (formal classes and informal conversational classes). In it the researcher tried to do some introspection of how learning was perceived and record the most salient aspects of her learning experience. These entries were written in a semi-systematic way, that is, both learner and researcher usually recorded the data sometime after the classes or after their individual reviewing process.

The learner is an experienced EFL teacher who speaks three languages fluently: Spanish, Lithuanian, and English. Her native language is Spanish and she learned Lithuanian during her early years

at home with her parents who are Lithuanians. English was learned 
later at the age of 8 when the whole family moved to the USA. Her brother, sisters and herself. before coming to the USA studied for a few months in an American school where all subjects were taught in English. They acquired at this school very basic skills. She remembers having a hard time understanding the language the first three months, but after attending regular school classes she started to understand and communicate without problems. She lived in the USA till the age of 12. She mastered the English language very well, speaking it fluently and accurately having hardly any foreign accent.

In her undergraduate years she studied one semester of French where she was considered a very good learner and got the highest mark in her class. One aspect that called her French teacher's attention was that English rather than Spanish was interfering in her pronunciation.

Having acquired a lot of metalinguistic knowledge through the undergraduate and graduate program as well as through the years of experience as an EFL teacher. She thought that it would be interesting to find out what learning and communication strategies she would use in learning an unknown language, what kind of metalinguistic knowledge she would employ to aid in learning; and what inferences and hypothesis she would make during the learning process.

\section{ii) The teacher}

The researcher of the present study is from Saudi Arabia. He holds a BA in English from a Saudi Arabian University as well as an MA in TESOL and a Ph.D. in Rhetoric and Linguistics from an American University. The researcher has had a good experience in teaching EFL approximately twenty years and has taught EFL in Saudi Arabia at different levels from elementary school to College level. Besides teaching English he has also taught Arabic and Islamic courses in elementary schools.

During his graduate studies he has been able to teach on weekends Arabic in different Islamic centers. His third language is Urdu. He learned Urdu when he was in Pakistan from 1980 to 1981. Although he did not use: Urdu for a long time but still he can understand and communicate with people speaking that language. The researcher was in charge of providing the syllabus and the instruction throughout the four-week period of class. He would design activities that will help promote the learning of Arabic. He would also monitor the researcher-learner's progress and keep a diary of the aspects observed in class. In addition, at the end of the program he 7 
would apply a speaking and listening test with another colleague to see how much was learned and the level of proficiency reached Data sources.

Multiple sources of data were used, so besides diaries that were kept (one by the learner and another one by researcher) there were also tape recordings of the formal classes and this data was triangulated which helped towards the issue of 'credibility' and 'transferability' in the data analysis. The recordings were used by the learner to go over the class and be able to relive the moments enjoy experienced and write down the elements that were taking place at the precise instant. It worked functioned as a self-stimulated recall.

\section{iii) The Language}

The selection of the Arabic language was selected on the basis that the learner had no previous knowledge of this language and that the researcher is a native speaker of this language. This lack of previous knowledge will enable us to see what elements the leamer employs to learn the Arabic language and how these elements were used facilitate or complicate her learning process.

\section{iv) The Classes}

The objective of these sessions were to help the learner learn some language, acquire skills to be able to communicate basic needs, express personal feelings, acquire information, socialize and comprehend basic vocabulary and structures. The classes took four weeks of formal instruction of twice sessions per week, each session continued for 45 minutes A Saudi Arabic dialect was taught twice a week in two pedagogical hour slots. These classes were taught using an individualized program course designed by the researcher using the communicative approach. In this course the learner and the researcher worked together on a one-to-one basis and only the oral language was taught. The reason for excluding the written language was due to the complexity that this would bring such as having not only to learn all the new sounds and structures in Arabic but a new alphabetic system of writing as well. Furthermore, another aspect taken into account was the short time the individualized program was used (16 pedagogical sessions of 45 minutes each), so due to these factors no written language was employed. To keep track of the oral language taught to her, the learner transcribed all lexical items, expressions, and structures and kept a record of them. She tried to use IPA transcription as much as possible. These transcriptions served as the only source for 
her individual learning, studying and way of reviewing the materials taught in class. All classes were tape-recorded.

Among the materials used in class there were handouts made by the reseacher that contained the English script of the dialogs where the learner would transcribe the Arabic version. Furthermore, the teacher taped dialogs with another native speaker of Arabic. These recordings were used in class for listening and for the learner to take home and practice.

Besides the scheduled classes there were also 2 hours of informal conversation classes twice a week where the learner practiced conversing with a native Arabic woman by going out to different settings such as supermarkets, coffee shops, restaurants, department stores, etc. Furthermore, there were two visits to a Saudi Arabian women's social gathering (See Appendix A). These gatherings worked as a natural communicative setting where the learner was exposed to authentic language and served as a practice medium as well as a source of comprehensible input

As far as testing instruments used in this program, there was no pretest because as it was explained previously the learner had no background knowledge of Arabic. There was a final oral test. This test tried to assess the vocabulary, phrases, expressions and structures learned during the teaching period. The test consisted of two parts, one for speaking and the other for listening. The former included picture descriptions, role-plays, and questions and answers. In the latter, recognition of pictures, understanding the main idea and some discrete information from an oral text, follow conversations and understand messages that concern everyday life activities, etc.

\section{v) Analysis}

The class recordings and the diary were scanned and analyzed to find patterns, regularities or salient events that could emerge from these data that would indicate the kind of strategies employed in learning Arabic as well as the kind of metalinguistic knowledge used and how it aided in the learning process.

The different data sources (class recordings, learner diary and teacher diary) were triangulated in order to obtain 'credibility' and 'transferability'. A thorough description of the setting, situation and participants (voices) was provided.

In this case study, the teacher described and analyzed a shortterm course in Arabic that we called "Survival Arabic". It is Survival 
because it focused on the essentials of spoken Arabic that would suffice a non-Arabic speaking person to live and use the language to fulfill the learner basic needs like shopping, reserving a hotel, calling a cab, etc. The purpose of this study was to observe the strategies that the teacher used to teach a Saudi Arabian dialect to an experienced $\mathrm{EFL}$ teacher as well as to observe the aspects in the language learning process that facilitated the her learning or cased difficulties.

\section{Findings}

\section{From learner perspectives}

Different findings emerged from data analysis. These findings are: (1) varied learning strategies used in learning productive skills in Arabic; (2) the limited strategies used to aid her communicate her ideas in real communicative settings; Arabic.

Varied learning strategies used in learning productive skills in

Following Oxford (1990) classification of strategies The researcher found that most of learners' strategies used were direct strategies, those that need mental processing of the language, summing up to a total of 107 strategies used. The most common direct strategies used were the cognitive ones $58 / 107$, representing $53.21 \%$ of all the direct strategies used (see Table 1), followed by memory strategies $35 / 107$, representing $32.11 \%$ and finally compensation strategy which yielded $16 / 107$, representing $14.6 \%$.

Looking closely at the cognitive strategies (see Table 2) it was found out that 'analyzing and reasoning strategies' and 'practicing' encompass the main type of cognitive language learning strategies used. The former produced $30 / 56$, which represents $53,57 \%$ and the latter $26 / 56$, which represents $46,43 \%$. Oxford (1990) points out that analyzing and reasoning strategies are among the most commonly used strategies used by adult language learners because they "tend to 'reason out' the new language. They construct a formal model in their minds based on analysis and comparison, create general rules, and revise those rules when information is available" (p.44). From the learner diary The researcher found multiple instances where she was 'reasoning deductively' -"using general rules and applying them to the new target language situation" (Oxford, 1990, p. 46). "This strategy involves deriving hypotheses about the meaning of what is heard by means of general rules the leamer already knows" (p.82). For instance: 
When we were practicing the form "What's your name?" Ali told me to ask his wife the question and I remember from a conversation we once had that for females you add /i/ at the end and so I said / I ismáki/ ? and Ali was surprised and I told him that I remembered that his wife had told me this when she told me the word "drink " in Arabic. (p.1)

Once I knew the gender of the words I was able to predict most of the dual for the words. I remembered from a previous class that Ali had told me that feminine in the dual take the sound / $/$ / and you add /ein/ so I was able to predict most of the duals correctly. (p.10)

Then I realized something about bad in behavior that it started similar to ugly $/ \mathrm{mah} /$ but the difference is that one is followed by $/ \mathrm{i} /$ and the other by / $\mathrm{u} / \mathrm{I}$ suppose that the one with/i/ is probably a feminine word and the one with $/ \mathrm{w} /$ is a masculine one (p.11)

He asked me to say wife from husband and I successfully predict that by just adding the $/ a /$ at the end it would be wife. (p.16).

We then went on to asking "how many brothers/sisters/aunts/uncles/cousins/ do you have? When I was in class I didn't realize that in Arabic we did not use the plural forms but singular in the questions. I need to find out if it was a mistake or that's the way it is in Arabic. (p.16).

I transcribed all the pronouns in the sentences and questions that he mentioned and placed as he had said those that belonged to me, those that referred to you (male and female), those that referred to her and those that referred to he or him (which he only mentioned one). Looking at them transcribed I can only come up with that when I refer to myself the pronoun is at the end and ends in $/ \mathrm{i} /$ or $/ \mathrm{ja} /$. When it refers to you there is a $/ \mathrm{k} /$ at the end but if we refer to a female we add an $/ \mathrm{i} /$ to the $/ \mathrm{k} /$.When we refer to her we use /mahá/ at the end and when it is male $/ \mathrm{mu} /$.Now I would have to test with Ali all these endings with family members to see if it applies. That's what I'll do next class.(p.i7)

Then he also he gave the plural for 'stand up' and 'sit down'. I repeated after him these words several times in singular 
feminine, and plural. Now that I am reviewing $I$ see that these two plurals end in $/ \mathrm{u} /$ none of the words I had seen had such a plural ending maybe it is because these two are verbs (p.27)

The researcher also found out that the learner used a rather significant amount of 'analyzing contrastively' strategy. Oxford (1990) mentions that this strategy tends to be used very naturally by beginners. It refers to looking for similarities and differences in comparison to one's own first language (L1). In her case she tended to associate with not only my L1 Spanish but also with her other two languages Lithuanian and English:

We also started with naming objects and the forms 'Singular: What is this? What is that? Dual: What are these? Plural: What are these? What are those?. He explained that in Arabic there is dual, but in other languages, this does not exist so, this a new concept for me. He also explained to me that gender is pointed out in singular, dual and plural. Ali goes into a lot of useless explanations for me. I perceived /haza/ as /hada/ instead of the interdental voiced fricative. Ali corrected me. I was curious and asked if they had many compounded words in Arabic but Ali said they had some but not too many. I explained that Lithuanian has most of its words compounded. (p.4-5)

I noticed that some words had different gender that the ones I had in Spanish for example 'door, chair' in Arabic are masculine while in Spanish they are feminine. While 'car' in Arabic is feminine in Spanish it is masculine. This confuses me but what can I do try to learn them. (p.5)

He then took out a card which had a lighter shade so I remembered that in the last class Ali had told me this so I looked into my notebook and stated 'light green' remembering that the order was that of Spanish 'verde claro' so I uttered the two Arabic words. Ali laughed and said very good. (p.6)

I tried to make a question stating 'how much is the black book?/ but I kept the English word order instead of saying /asued kitab/. I still need to practice this. I made the same mistake several times in the lesson. The rule has not been internalized yet English word order is prevailing. (p. 7)

I got a bit confused with the uncles and aunt. I mix up when it is mothers' side and father's side. It is much easier in 
English and Spanish where these differences exist but you can use just one word for them (p.21)

I asked him to clarify some doubts that I had on asking questions with "How many" I noticed that with questions with How many the singular form was used instead of the plural like Spanish and English. Ali explained that in Saudi Arabic the singular is used and people know that it is plural because of the word how many. (p.21) Now that I think it over yes in Spanish we do have this 'sientense' 'parense'. I understand now.(p.28)

I told Ali that I know that I tend to place $/ \mathrm{n} /$ instead of $/ \mathrm{m} /$ at the end of words like in 'bathroom' in Arabic because in Spanish we hardly have (or we don't have I'm not sure) final words with $/ \mathrm{m} /$. So I'm aware of some of my probable problems and I understand why I have them. (p.28)

\section{From Teacher Perspectives}

The main findings can be summarized in the following:

1) The need of an eclectic methodology that emerged from the short Arabic program.

2) Characteristics of "a good language learner" that were displayed by the learner of this study.

3) Specific language problems that the learner confuted when learning A Saudi Arabian Dialect.

The need for an eclectic methodology that emerged from the short Arabic program.

At the very beginning and before we started this study the teacher was planning to use the communicative approach in his teaching, but when he started the classes, the teacher found out that he was using repetitions more. That made him ask himself if he was doing audiolingual approach. In audiolingualism Blair (1991) reported:

... language was viewed largely as a definable set of structures with lexical exponents, which could be learned inductively, pattern by pattern, by means of a rigorously planned and carefully executed program of instruction based on the laws of conditioning and reinforcement. (p.24)

This made the teacher think again if what he did was effective or not. Should the teacher follow the audio-lingual method? In an 
attempt to interpret this, the teacher would say that this pattern drill practice was more appropriate and consistent with the behaviorism theory of language learning. Language is learned through imitation and repetition. It is a habit formation process. An outlandish interpretation could be that since this is the most prevalent method, the Audio-Lingual Method in Saudi Arabia, and since this is how the teacher taught EFL,

However, in this case study the teacher used translations most of the time but not following exactly grammar-translation method. He followed some of grammar-translation's technique in his teaching; like giving the instruction in the native language of the students (English in this situation) or translating sentences from the target language (Arabic) into the mother tongue(English) (Celce-Murcia 1991). He thought that the learner should acquire a good vocabulary that can help her in future to make complete sentences. The researcher tried to break the rules and use multi-approaches that he learned in his EFL teaching experience. In this context, Fanselow(1987) supports breaking rules for the sake of innovation and interesting learning.

As we explore, 'rather than seeking prescriptions and judgments from others, rules (can be) broken that we teachers must seek alternatives from those in charge, rather ourselves or our peers, and that we must work alone within our autonomous isolated and lonely classroom, rather than with colleagues. (p.7)

Similarly, Long (1991) supports non-traditional, multi methods that create innovation in teaching. He observes "...many have stopped pretending that any one method is a panacea or at least that they know which one is, most nevertheless continue to use method as a unit of analysis in their professionally oriented courses" (p.39)

Besides these various methods, I tried to fuse in my teaching some important cultural aspects from the Arabic culture in order to not only motivate and making learning more interesting but to help the learner how this language is intertwined very deeply with cultural factors; like greetings which are long in Arabic culture.

I believe the most important thing in Arabic culture and in any other culture is greeting. I agree that in Arabic we use a lot of greeting phrases and words. In Saudi Arabia and most of Islamic World we start greeting with /as salaam alykum/ السالم عليكم/ which means "peace be upon you." Then we move to /marhab// /

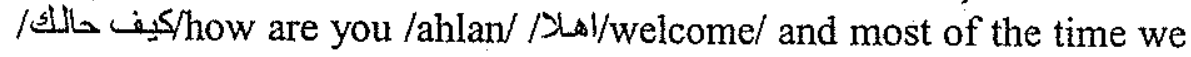
14 ask about the health and family members. Culturally, a Saudi want s 
to show guests that they are warmly welcome. I like very much what Gebhard says about this trait in Arabic culture: ".... human interaction is more highly valued than being on time" (p.114) In every class I was aware enough to teach her the value of greeting and review that with her at every beginning and ending for each class.

$\mathrm{J}$ found greeting very difficult and too long to use. Unlike Arabic, greeting in English and Spanish is short and quick. When I started teaching her greeting, she paid a little attention to that. I tried to come over this by practicing greeting in the beginning of each class. $I$ also went beyond that by using Arabic greeting when I met her in class or talk to her on the phone. This technique succeeded and made her use greeting automatically with my wife without asking her to do so.

\section{From the first meeting}

$\mathrm{J}$ learned how to greet people in Arabic and even practiced the greeting with my wife. I wanted her to feel comfortable and relaxed to make her learning experience easier so she can learn faster and it also gave her the chance to practice what she is learning with my family.

When I asked her that we are going to get more greeting phrases, I noticed her surprise when she asked how many greetings do we have in Arabic? I told her that there is some sort of greeting for every occasion.

\section{From the eighth meeting}

In this clas' I taught her a new way of greeting. I explained to her that Arabs like to greet each other a lot especially if he/she is well known to the person. We have some words we use in the morning and others in the evening. We do not have anything for the afternoon and this "good afternoon" caused a lot of trouble for me when I taught English as a foreign language in KSA. I did not know how to translate this term into Arabic. In Arabic we have "good morning" and "good evening", but we do not have "good afternoon". Anyhow I explained to $J$ this concept.

In Arabic we have a special greeting response for "good

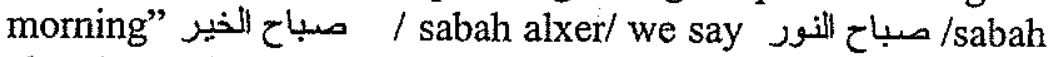
alnor/ and for "good evening"/masa alxer/ مساء الخير الخرر we say /mas alnor/ مساء اللنور. 
In this regard Porter and Samovar (1996) explained "Culture enables us to make sense of our surroundings, adding the translation from the womb to this new life. "(p.12). And they also added "From how to greet strangers to how to spend our time, culture provides us with structure." (p.12).

On the other hand, the learner has been a good learner in the sense of

her ability to use different techniques and approaches to facilitate her learning. As Michael H. Long (1991) argues in Focus on Form: A Design Feature in Language Teaching Methodology,

A good learner will attempt to discover for himself his preferred techniques or his particular learning strategy so as to make his own language learning'more satisfying. It follows that he is also prepared to learn from his or other people's experience and to modify his approach accordingly (p.311).

Hence, The researcher believe the learner's long experience with teaching methodology has facilitated the use of reciprocal (the interaction between the teacher's methodology and the learner's methodology) and has also helped in making learning easier. "The good language leamer has sufficient linguistic knowledge to face up realistically to difficulties and complexities of the second language. He understands that and therefore makes an active effort to understand rationally the new L2 reference system and to accommodate himself to it emotionally" (H.H. Stern: What can we learn from the good language learner? (p.313)

\section{Characteristics of "a good language learner" that were displayed by the learner of this study}

In the literature review of this paper, the reader will notice the rich background $J$ has in linguistics and second language learning. This excellent background can be seen clearly in her strategies. From the very beginning she used a linguistic chart in all the meetings. I gave her a chart of IPA and a chart of Arabic sounds. She found these charts very helpful to her.

I consider $\mathrm{J}$ a very good learner. Her long teaching experience as well as her sophisticated knowledge of teaching methodology and Linguistics background made her acquire the language quickly. I noticed that she adopted these experiences in her learning of this new language. Her approach was through transcription. She used to 16

transcribe everything in the class. This was the way she learned the 
language. In this regard, Stern (1980) says, "A good learner will attempt to discover for himself his preferred techniques or his particular learning strategy so as to make his own language learning more satisfying. It follows that he is also prepared to learn from his or other people's experience and to modify his approach accordingly" (p.311)

Association is another strategy that the learner used. She tried most of the time to find out ways to link Arabic to Spanish and Lithuanian. Comparing between J L1 (Spanish \& Lithuanian) and Arabic was one of the most amazing things I found. She has a very good ear to notice the new sounds and new words in Arabic and then tries to associate this new word with her native language (Spanish \& Lithuanian). For example she associate six in Arabic with seven in Spanish which are the same pronunciation $/$ seta $\%$. And when I taught her how to say, "which city are you from?" She told me that this sounded similar to Spanish /ahi medina/ in one of our classes I was talking to my wife to reduce the heat /drana/, J told me we have the same pronunciation in Lithuanian for some crazy person.

\section{Specific language problems that the learner confuted when learning the Saudi Arabian Dialect}

\section{1) Numbers}

I believe that numbers are very important in any language. Learning the numbers is the easiest thing the learner can start with. We started the first two classes with numbers. The funny thing in Arabic scripts that we use the Indian numbers in Arabic while the Western world uses the Arabic numerals. I tried to explain to J that in Arabic, it is the opposite of English. For example if I am saying the number "twenty one" in Arabic, I should say it "One and twenty. I used numbers in most of my classes especially when I taught her the prices and how to use them. The learner used her main strategies to acquire the numbers. $J$ tried to find links between the languages she knew and Arabic. She found two numbers are sounded like Spanish; six one hundred and one thousand. Her association strategy worked very well for numbers .

In Arabic, it is the opposite of English. For example if I am saying the number "twenty one" in Arabic, I should say it "One and twenty" (واحد و عشرين) At the very beginning of the classes I noticed that she constantly forgets to say /wa/ \& between the numbers; she used to say/wahed ashreen/ (واحد عشرين) instead of /wahed wa ashren/ (واحد و عثردي). 


\section{Example I: From the third class}

After I was sure that she understood the numbers from 1 to 20 $(Y+-1)$, I added the numbers from 20 to $100(1 \cdots-Y \cdot)$. I explained to her the rule in Arabic of saying these numbers. In Arabic, it is the opposite of English. For example if I am saying the number "twenty one" in Arabic, I should say it "One and twenty" (واحدو عشرين) I noticed that she constantly forgets to say /wa/ g between the numbers; she used to say /wahed ashreen/ (واحد عشـرين) instead of /wahed wa ashren/ (واحسد و عثــي (و). I tried to draw her attention to this by repeating the words' or by asking her to say it again. Still I can hear her saying the numbers without adding /wa/, between the numbers. At this point I told her directly that she is neglecting the $/ \mathrm{wa}$ / between the numbers.

The teacher recognized that the learner mixed between two numbers three /thalatha/ / $/$ / This kind of mixing made the learner come up with new number which she called /thalamia/.

\section{2) Masculine and Feminine}

Arabic is different from English in two things. The first difference relates to gender while the second is about the plural. Like French, Arab has separate nouns for the male and the female genders.

$J$ told me that in Spanish; there are masculine and feminine words. So the learner did not have difficulty understanding this concept. J not only understood this but also was able to develop a strategy for the rest of the classes. When the teacher named any object in masculine form, the learner directly changed it to feminine to show that she understood the rules.

\section{Example II: From the second class}

We then moved to another step in our learning. The new step was about naming and making questions about objects. I began by asking, "what is this?" /aeesh hatha/ (يش) iis) and then explained that Arabic is different from English in two things. The first difference relates to gender while the second is about the plural. Like French, we have separate nouns for the male and the female genders. Arabic has also singular, dual and phural nouns for the genders. 


\section{3) Dual in Arabic}

Unlike English, Spanish or Lithuanian, Arabic has singular dual and plural nouns. This was the first time for $\mathrm{J}$ to learn about dual. Thackston (1994) stated that dual: "For two of anything Arabic employs the dual number, which is completely regular in its formation" (p.19). There is a nominative suffix and oblique suffix. The dual normative suffix, which is added to the base of the noun (i.e., the noun without its inflectional endings), is /an/ stated in words man /ragul/ becomes men /ragulan/ and woman /almarat/ becomes women /almaratani/. For the dual oblique (genitive and accusative) suffix is /ayni/ the same for man and women in deferent setuation/rajul/ dual is /rujulayn/ and /amr / . Although, we did not go deeply in the grammatical issue of the dual usage $J$ not only got the idea very quickly but she also tried all the times to apply that in every word she learned.

\section{4) Pronunciation}

In Arabic there are 28 consonants and nine vowels. (See appendix). Philps (1995) notice that:" ... they are 28 consonants and they are preannounce according to the first letter of their names" (p.13).

During these lessons, $\mathrm{J}$ had a hard time pronouncing two sounds $/ \mathrm{h} /$ and $/ \mathrm{\%} /$. These two phonemes do not exist in either English or Spanish. Ziaded and Wnder (1957) defined $/ \mathrm{h} / / /$ as: lower than $/ \mathrm{x} /$

An unvoiced pharyngeal fricative formed further back and

$/ \dot{\gamma} /$ and entirely without velar vibration. The back of the tongue is depressed to almost the same extent it is when a doctor examines the throat and depresses it artificially. The sound may be mastered by realizing that it is similar to a stage whisper, but formed farther back. It can be produced by whispering ha as loudly as possible. (p.4)

They also defined $/ \& / / \varepsilon /$ as: "It is generally regarded that $/ \$ / \mid \varepsilon /$ is a voiced correlative of $/ \mathrm{h} / / \mathrm{\gamma} /(\mathrm{p} .5)$. I also noticed that she found a way to deal with this problem. She used the chart and her hands to find out the place of these two sounds. The can be seen from the second meeting and continue for most of the classes. I explained to her that with more practice, she could be able to pronounce these sounds. 
J started the class by greeting everyone in the house in Arabic. I noticed that she can hardly pronounce the two letters $/ \mathrm{h} / \tau / \mathrm{I} / \varepsilon$.

The learner used her own strategy to solve this problem. The strange thing was that she could pronounce these sounds individually.

\section{Example III: From the third meeting}

She asked about the places of some sounds on the phonetics chart we have. Every sound I made, she asked me to show her from where this sound came. I notice that she used her hands to feel the vibrations of the voiced or voiceless sounds. She did that to make sure that she found the right place of sounds.

\section{Example IV: The fourth Meeting}

I noticed that she still had some difficulties saying the letters $/ \mathrm{h} /$ and $/ \% /$. She mixed between $/ \mathrm{h} /$ and $/ \mathrm{x} /$, and she also mixed between $/ \& /$ and $/ \mathrm{K} /$. When I listened to the tape that I recorded during the class, I found out that she could not say the sounds of $/ \mathrm{h} /$ and $/ \% /$, which are voiceless and unstressed in Arabic. The farthest she could go was to say $/ \mathrm{K} /$ and $/ \mathrm{X} /$. These two sounds $/ \mathrm{K} /$ and $/ \mathrm{X} /$ are voiced and above $/ \mathrm{h} /$ and $/ \% /$. I explained to her that with more practice, she will be able to pronounce these sounds.

\section{Example V: The seventh meeting}

She agreed with me that the sound of $/ \mathrm{h} /$ and $/ \cong /$ are the most difficult sounds she met.

As a strategy I told her to use $/ \mathrm{h} /$ for $/ \mathrm{h} /$ and $/ \mathrm{a} /$ for $/ \mathrm{s} /$ and that will help people understand her although she still sounds foreign. I explained to her that I have hard time with my accent in English. Although I know this strategy might cause her some embarrassment, this is the only way at this time to get over her problem.

\section{5) The test}

There was no pre-test for this study because the learner has no background in Arabic. This was the first time the learner learns Arabic. At the middle of this course, I set a quiz to test what the learner has acquired. The learner was the one who asked for the quiz to test her memorization abilities. In the quiz, I gave her words written in English and asked her to say them in Arabic. There were three questions and each question contained eight words. The last question was more advance as it contained two phrases. 
For the final exam, it was different. The exam has two main parts: listening and speaking. For the listening test, I recorded a tape for that purpose. There were two questions the first one was about the numbers. I recorded the numbers and asked her to circle the number she heard. Out of 15 numbers she got 14 numbers correctly. In the second question, I tried to test her listening ability and find out if she can understand the whole numbers in different orders. I also tried to combine the numbers $(3 \& 8)$ she used to mistake all the times and mix them in a three-digit number, but again she missed one of theses numbers that contain the two numbers within (683).

The second question in listening was completely different. In this question, I tried to examine her understanding in communication. I recorded a conversation between my wife and me that mimicked a real conversation in a store selling clothes. While listening to the recorded conversation, she had a multiple choice questions to choose the correct answer. For each question, there were four choices that have one correct answer. I asked her about place, time, color and price. Except for colors, she correctly answered the four questions. She justified that she learned one way of saying colors and that was not the same one she heard on the conversation. When I went back to my journals, I found that was true, so I exclude that question from the test.

The second part of the exam was on pronunciation. In this part, the learner had to speak and say the numbers for the first questions. Again I noticed that she mixed the numbers 3 and 8 . Ironically, she came up 'with a possible number, /thalamia/. In question 2, there were pictures and I asked her to give the names of each picture in Arabic. She did very well in this part except for saying the word "cucumber", because the picture was not so clear and she thought it was a "banana." But when she read the word under the picture she said it correctly. The third question for the speaking part was to role-play with me and pretend that I am a friend she met in the mall carrying futures in my hand. I asked her to start with greeting using the morning greeting after saying hi and following the parts of greeting she learnt. In this question, I was testing her ability to use a semi-real language situation that she could have been into it. In this exam, I was trying to find out how much does the learner got form 12 hours meeting during the last four weeks. And I was also trying to make sure if the learner has got onto the first step of communication. 
In conclusion it appears that diaries are useful research tools because they show us what is significant to both the teachers and the learners through the retrospective endeavor, which by conventional research methodologies would be unattainable. I believe that was a fascinating experience. It is very good thing to learn new languages and master them. Personally, I hope to learn more languages so that I can understand the cultures of these languages. In Islam, learning languages is highly recommended. My teaching experience with the learner has been very beneficial for both of us. We have both learned from each other and have agreed, if there is a chance in the future, we will continue this work.

\section{Appendix}

Table 1. - Direct and Indirect Strategies used

\begin{tabular}{|c|c|}
\hline Strategies & : Total \\
\hline I.-Direct: & 107 \\
\hline Memory & 35 \\
\hline Cognitive & 56 \\
\hline Compensation & 16 \\
\hline II.-Indirect: & 78 \\
\hline Metacognitive & 45 \\
\hline Affective & 18 \\
\hline Social & 15 \\
\hline Total & 185 \\
\hline
\end{tabular}

Table 2. Direct Strategy: Cógnitive Strategies used in both settings

\begin{tabular}{|l|c|c|}
\hline Cognitive Strategies & Total & $\%$ \\
\hline A.-Practicing: & 26 & \\
\hline 1.Repeating & 13 & \\
\hline 2.Practicing naturalistically & 13 & \\
\hline B.-Analyzing and reasoning: & 30 & \\
\hline 1. Reasoning deductively & 12 & \\
\hline
\end{tabular}




\begin{tabular}{|l|c|c|}
\hline 2. Analyzing expressions & 5 & \\
\hline 3. Analyzing contrastively & 11 & \\
\hline 4. Transferring & 2 & \\
\hline Total & 56 & \\
\hline
\end{tabular}

\section{References}

Bailey, K. M. (1980)..An introspective analysis of an individual's language learning experience. In S. Krashen, \& R. Scarcella (Eds.), Research in second language acquisition: Selected papers of the Los Angeles second Language Research Forum. Rowley, Mass: Newbury House.

Bailey, K. (1983). Competitiveness and anxiety in adult SLA: Looking at and through the diaries studies. In Selinger and Long, (Eds), Classroom oriented research in SLA. (pp. 67-102). Rowley, Mass: Newbury House.

Bailey, K. M., and Ochsner, R. (1983). A methodological review of diary studies: windmill tilting or social science? In K. M. Bailey, M.H. Long, and S. Peck (Eds.), Second language acquisition studies. Rowley, Mass: Newbury House.

Brown, C. (1985) Two windows in the classroom world: Diary studies and participant observation. In P. Larsen, E. Judd, and Meserschmitt (Eds.), On TESOL 184: A Brave New World for TESOL (pp. 121134). Washington, D.C.: TESOL

Cohen, A. (1984). Studying second-language learning strategies: How do we get the information? Applied Linguistics, 5 (2), 101-112

Felix, S. (19). The effect of formal instruction on second language acquisition. Language Learning, 31(1), 87-112.

Hosenfeld, C. (1976). Learning about learning: Discovering our students' strategies. Foreign Language Annals, 9 (2), 117-130.

McLaughlin, B.; Rossman, T. and McLeod, B. (1983). Second language learning: An information-processing perspective. Language Learning, 33 (2), 135-158. 
Rees-Miller, J. (1993). A critical appraisal of learner training: Theoretical bases and teaching implications. TESOL Quarterly, 27 (4), 679-689

Rivers, W. (1979). Learning a sixth language: an adult learner's diary. Canadian Modern Language Review, 36 (1), 67-82.

Rubin, J. (1975). What a good language learner can teach us. TESOL Quarterly, 9 (1), 41-50

Schmidt, R.W. and Frota, S.N. (1986). Developing basic conversational ability in second language: A case study of an adult learner of Portuguese. In R.R. Day (Ed.), Talking to learn conversation in second language acquisition, (pp. 237-326). Rowley, Mass: Newbury House.

Seliger, H. (1983). The language learner as linguist: Of metaphors and realities. Applied linguistics, 4 (3), 179-191.

Stern, H.H. (1980). What can we learn from good language learners. Canadian Modem Language Review, 304-318 


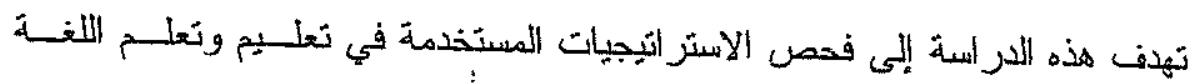

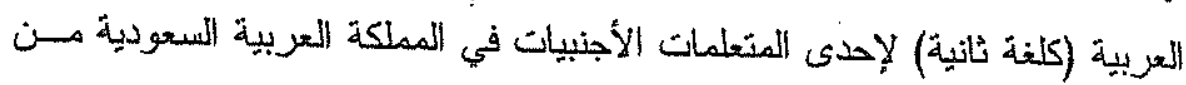

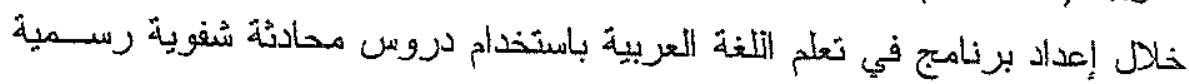

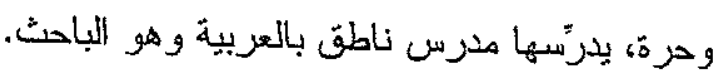
وكان الغرض من هذه الار اسنة ملاحظة مايلي: أ) استر اتيجيات التعلم و المتو امل المتبعة بواسطة المتعلم،

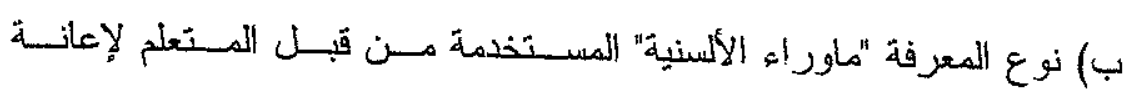
المشاركين في تعليمه،

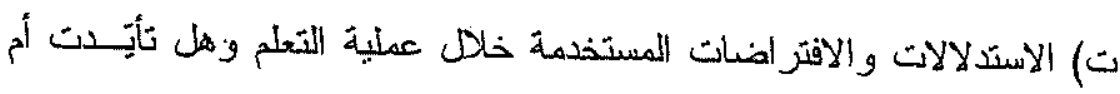

وكانت اللغة الأصلية للمتعلمة المشاركة هي الإسبانبة، وكانت تنكلم بطلافة أيضسا

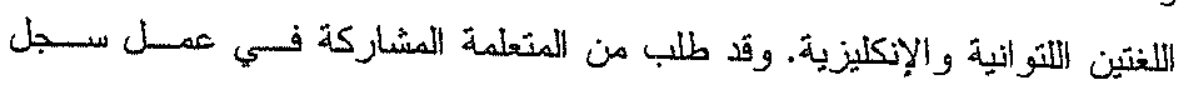

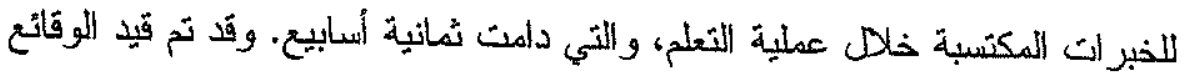

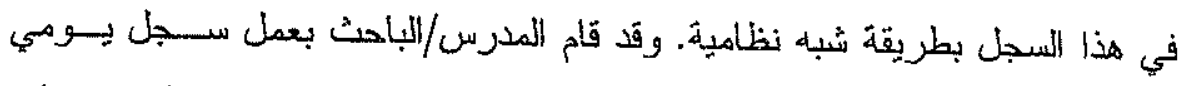

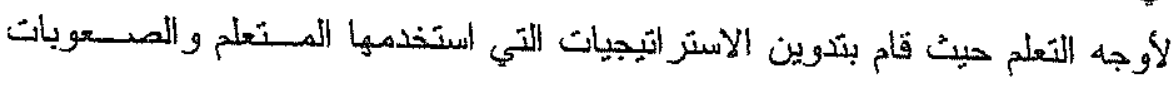
الثي واجهها أثناء عملية تعلم اللغنة. وقد تم تحليل كل من السجلين للحمبول على كل من الأنماط و الاطر الد والأحسـاث المثميزة. وقد تم هذا بافتر اض أن هذه التحليلات سنبين أن هناك عدة الستر اتيجيات قد التبعت، مثل استر اتيجية التذكر والاستز اتيجيات المعرفية وماور اء المعرفية. 
